\title{
Flow diversion of tandem cerebral aneurysms: a multi-institutional retrospective study
}

\author{
Al-Wala Awad, MD, ${ }^{1}$ Karam Moon, MD, ${ }^{2}$ Nam Yoon, MD, ${ }^{1}$ Marcus D. Mazur, MD, ${ }^{1}$ \\ M. Yashar S. Kalani, MD, PhD, ${ }^{1}$ Philipp Taussky, MD, ${ }^{1}$ Cameron G. McDougall, MD, FRCSC, ${ }^{3}$ \\ Felipe C. Albuquerque, MD, ${ }^{2}$ and Min S. Park, MD'
}

1'Department of Neurosurgery, University of Utah Health Care, Salt Lake City, Utah; 'Barrow Neurological Institute, Phoenix, Arizona; and ${ }^{3}$ Swedish Neuroscience Institute, Seattle, Washington

\begin{abstract}
OBJECTIVE Flow diversion has proven to be an efficacious means of treating cerebral aneurysms that are refractory to other therapeutic means. Patients with tandem aneurysms treated with flow diversion have been included in larger, previously reported series; however, there are no dedicated reports on using this technique during a single session to treat this unique subset of patients. Therefore, the authors analyzed the outcomes of patients who had undergone singlesession flow diversion for the treatment of tandem aneurysms.
\end{abstract}

METHODS The authors conducted a retrospective review of flow diversion with the Pipeline embolization device (PED) for the treatment of tandem aneurysms in a single session at 2 participating medical centers: University of Utah, Salt Lake City, Utah, and Barrow Neurological Institute, Phoenix, Arizona. Patient demographic data, aneurysm characteristics, treatment strategy and results, complications, and follow-up data were collected from the medical record and analyzed.

RESULTS Between January 2011 and December 2015, 17 patients (12 female, 5 male) with a total of 38 aneurysms (mean size $4.7 \pm 2.7 \mathrm{~mm}$, mean $\pm \mathrm{SD}$ ) were treated. Sixteen patients had aneurysms in the anterior circulation, and 1 patient had tandem aneurysms in the posterior circulation. Twelve patients underwent only placement of a PED, whereas 5 underwent adjunctive coil embolization of at least 1 aneurysm. One PED was used in each of 9 patients, and 2 PEDs were required in each of 8 patients. There were 2 intraprocedural complications; however, in both instances, the patients were asymptomatic at the last follow-up. The follow-up imaging studies were available for 15 patients at a mean of 7 months after treatment (216 days, range 0-540 days). The mean initial Raymond score after treatment was $2.7 \pm 0.7$, and the mean final score was $1.3 \pm 0.7$.

CONCLUSIONS In this series, the use of flow diversion for the treatment of tandem cerebral aneurysms had an acceptable safety profile, indicating that it should be considered as an effective therapy for this complicated subset of patients. Further prospective studies must be performed before more definitive conclusions can be made.

https://thejns.org/doi/abs/10.3171/2017.2.FOCUS1731

KEY WORDS Pipeline embolization device; tandem aneurysms; endovascular; flow diversion

$\mathrm{E}$ NDOVASCULAR intervention has proven to be a safe and efficacious means of treating intracerebral aneurysms..$^{9,15,27}$ The development of the Pipeline embolization device (PED; Medtronic) has enabled even further expansion of the use of endovascular treatment for aneurysms. ${ }^{3,5,23}$ Such devices have been used to successfully treat cerebral aneurysms by diverting flow across the aneurysm neck to decrease aneurysm wall stress without entering or manipulating the fragile aneurysm sac. ${ }^{17} \mathrm{Al}-$ though it is still early in the clinical use of these flow diverters, prospective trials have demonstrated their safety with high rates of aneurysm occlusion. ${ }^{16}$
The incidence of intracerebral aneurysms is estimated to be up to $3.2 \%$ in the general population, with as many as $34 \%$ of patients having multiple aneurysms. ${ }^{21,28}$ Within this cohort, a smaller group will have tandem, multiple aneurysms on the same parent vessel. Although this subset of patients has been successfully treated with endovascular coiling or surgical clipping, this unique arrangement of tandem aneurysms presents the opportunity to simultaneously treat multiple aneurysms during a single procedure. ${ }^{25,29}$ Here, we report outcomes in this unique patient subset through a multicenter effort to treat tandem aneurysms in a single treatment session using PEDs. 


\section{Methods}

After receiving approval from the institutional review boards at each institution, we performed a retrospective review of flow diversion with the PED to treat tandem aneurysms during a single treatment session. All adults treated in the period from January 2011 through December 2015 at 2 participating centers-University of Utah Hospital in Salt Lake City, Utah, and Barrow Neurological Institute in Phoenix, Arizona-were included in the study. Patient demographic data, aneurysm characteristics, treatment strategy and results, complications, and follow-up data were collected from the medical record and analyzed.

\section{Results \\ Patient Population}

Seventeen patients (12 female, 5 male) with a total of 38 aneurysms (average size $4.7 \pm 2.7 \mathrm{~mm}$, mean $\pm \mathrm{SD}$ ) were included in our cohort (Table 1). Sixteen patients had aneurysms in the anterior circulation, and 1 had tandem aneurysms in the posterior circulation. Fourteen patients had 2 tandem aneurysms, 2 patients had 3, and 1 patient had 4. Twelve patients underwent only placement of a PED, whereas 5 underwent adjunctive coil embolization of at least 1 aneurysm at the time of PED deployment. A single PED was used in each of 9 patients, whereas 2 PEDs were required in each of 8 patients. All patients were premedicated with $325 \mathrm{mg}$ of aspirin and $75 \mathrm{mg}$ of clopidogrel for 5-7 days prior to the procedure and continued on daily dual antiplatelet therapy for 6 months following the procedure.

\section{Outcomes}

There were 2 intraprocedural complications: a carotid dissection and a hemorrhage during adjunctive coiling. In both instances, the patients were asymptomatic at their last evaluation. Follow-up imaging studies were available for 15 patients at a mean of 7 months after treatment (216 days, range $0-540$ days). The mean initial Raymond score after treatment was $2.7 \pm 0.7$, and the mean final score was $1.3 \pm 0.7$ (Table 2). ${ }^{22}$

\section{Illustrative Case}

A 30-year-old woman (Case 16) with no significant medical history presented with long-standing headaches. Preoperative angiography demonstrated 2 saccular aneurysms along the right internal carotid artery (ICA) terminus (Fig. 1A). The patient was treated with 2 PEDs that spanned the necks of both lesions (Fig. 1B). There were no intraprocedural complications. Posttreatment angiograms at the 12-month follow-up demonstrated complete obliteration of both aneurysms (Fig. 1C).

\section{Discussion}

Flow diversion has quickly joined the growing list of treatment modalities for intracranial aneurysms. Although tandem aneurysms are rare, affected patients present a unique treatment dilemma for which flow diversion represents an attractive option. Impeding aneurysm inflow by flow diversion not only promotes aneurysm occlusion but also promotes repair of the parent artery to a more physiological state. ${ }^{10,30}$ Importantly, small branching feeders off the parent artery appear to remain intact even when covered by telescoping flow diverters, making these diverters especially useful when treating tandem aneurysms separated by a longer distance. $4,11,14,26,30$

We successfully deployed 25 PEDs to treat 38 tandem aneurysms in 17 patients. The average Raymond score at the last follow-up was 1.3, and $89 \%$ of treated aneurysms had complete occlusion at the last follow-up. Reports on the treatment of tandem aneurysms using the PED mostly consist of small series of patients or case reports. ${ }^{12,30}$ Lin et al. described 6 patients with 12 aneurysms who had a complete occlusion rate of $90 \%$ at the last follow-up (20 months). ${ }^{6}$

The ability to treat several aneurysms with a single or multiple telescoping PEDs is a unique advantage of flow diverters, limiting the amount of mechanical manipulation of the aneurysm that is associated with clipping and endovascular coiling. In our study, a single PED was used to treat each of 6 patients with 2 tandem aneurysms, 2 patients with 3 tandem aneurysms, and 1 patient with 4 tandem aneurysms. Eight patients each required 2 telescoping PEDs during the initial treatment.

In more challenging aneurysms, the use of a PED can be supplemented with adjuvant coiling. Five patients (10 aneurysms) in our study were treated with adjuvant coiling. They were treated toward the end of our series after the technique had become more prevalent in the literature. ${ }^{20}$ The use of a PED with adjuvant coil embolization has resulted in reduced retreatment rates in larger aneurysms and may have the added advantage of a higher obliteration rate in a shorter period of time..$^{18,20,26}$ Although acute and late thrombosis of aneurysms has been described in a limited number of patients with PEDs and adjuvant coiling, the safety and efficacy of this technique has been demonstrated in larger cohorts. $7,13,16,19,20,24,26$

Flow diverters also have the advantage of treating a wide range of aneurysm types. The treatment of fusiform aneurysms is significantly simplified through the use of a PED, with a high rate of success. ${ }^{8,13}$ However, no tandem fusiform aneurysms were treated in the present series. Pipeline embolization devices can also be safely used to treat small $(<10 \mathrm{~mm})$ aneurysms, as was the case in $92 \%$ of aneurysms in our series. ${ }^{2}$ Most recently, PEDs have even been used to treat ruptured aneurysms, further demonstrating their versatility in a wide range of settings, including acute interventions. ${ }^{1}$

As noted, there were 2 intraprocedural complications in our series: a carotid artery dissection and a hemorrhage during adjuvant coiling. In the latter case, the aneurysm was particularly small, which made the adjuvant coiling especially challenging. Both of these complications are known to occur with the endovascular treatment of aneurysms and appeared to be unrelated to the use of a PED specifically in tandem aneurysms. Fortunately, both patients were doing well at the last clinical follow-up.

\section{Conclusions}

The results of our small series suggest that the use of 


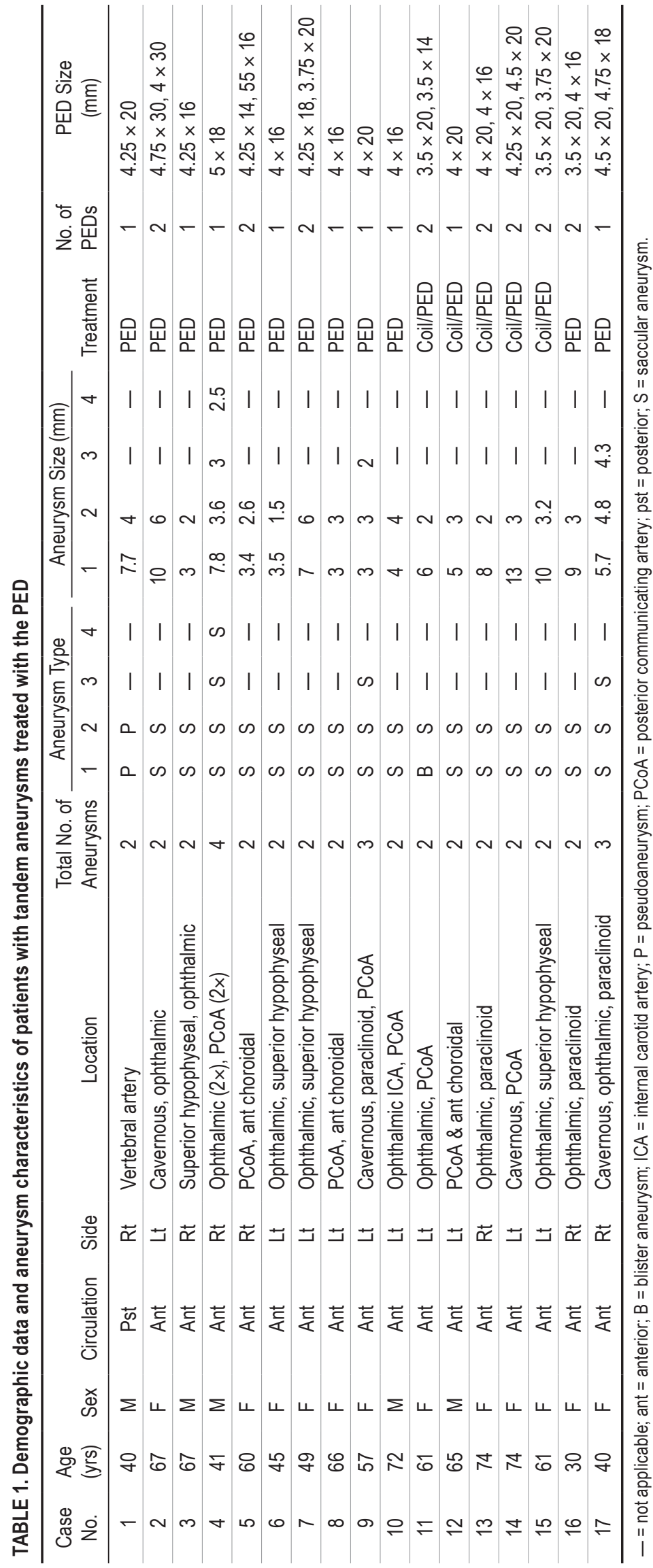


TABLE 2. Outcomes in patients with multiple tandem aneurysms treated with the PED

\begin{tabular}{|c|c|c|c|c|c|c|c|c|c|c|c|}
\hline \multirow{2}{*}{$\begin{array}{l}\text { Case } \\
\text { No. }\end{array}$} & \multirow{2}{*}{$\begin{array}{c}\text { Total No. } \\
\text { of } \\
\text { Aneurysms }\end{array}$} & \multicolumn{4}{|c|}{$\begin{array}{l}\text { Raymond Score Postdeployment } \\
\text { for Aneurysms 1-4, as Applicable }\end{array}$} & \multicolumn{4}{|c|}{$\begin{array}{l}\text { Raymond Score at Last FU for } \\
\text { Aneurysms } 1-4 \text {, as Applicable }\end{array}$} & \multirow{2}{*}{$\begin{array}{l}\text { Last } \\
\text { FU } \\
\text { (days) }\end{array}$} & \multirow[b]{2}{*}{ Complications } \\
\hline & & 1 & 2 & 3 & 4 & 1 & 2 & 3 & 4 & & \\
\hline 1 & 2 & 3 & 3 & - & - & 1 & 1 & - & - & 98 & None \\
\hline 2 & 2 & 3 & 3 & - & - & NA & NA & - & - & 1 & Lt ICA dissection \\
\hline 3 & 2 & 3 & 3 & - & - & 1 & 1 & - & - & 405 & None \\
\hline 4 & 4 & 3 & 3 & 3 & 3 & NA & NA & NA & NA & 107 & None \\
\hline 5 & 2 & 3 & 3 & - & - & 1 & 1 & - & - & 126 & None \\
\hline 6 & 2 & 3 & 3 & - & - & 1 & 1 & - & - & 42 & None \\
\hline 7 & 2 & 3 & 3 & - & - & 1 & 3 & - & - & 540 & None \\
\hline 8 & 2 & 3 & 3 & - & - & 1 & 1 & - & - & 420 & None \\
\hline 9 & 3 & 3 & 3 & 3 & - & NA & NA & NA & - & 0 & None \\
\hline 10 & 2 & 3 & 3 & - & - & 3 & 3 & - & - & 7 & None \\
\hline 11 & 2 & 3 & 3 & - & - & 1 & 1 & - & - & 360 & None \\
\hline 12 & 2 & 3 & 3 & - & - & 3 & 2 & - & - & 270 & Intraop hemorrhage \\
\hline 13 & 2 & 1 & 3 & - & - & 1 & 1 & - & - & 240 & None \\
\hline 14 & 2 & 2 & 3 & - & - & 1 & 1 & - & - & 210 & None \\
\hline 15 & 2 & 2 & 1 & - & - & 1 & 1 & - & - & 210 & None \\
\hline 16 & 2 & 1 & 3 & - & - & 1 & 1 & - & - & 365 & None \\
\hline 17 & 3 & 2 & 1 & 2 & - & 1 & 1 & 2 & - & 270 & None \\
\hline
\end{tabular}

$\mathrm{FU}=$ follow-up; $\mathrm{NA}=$ not available.
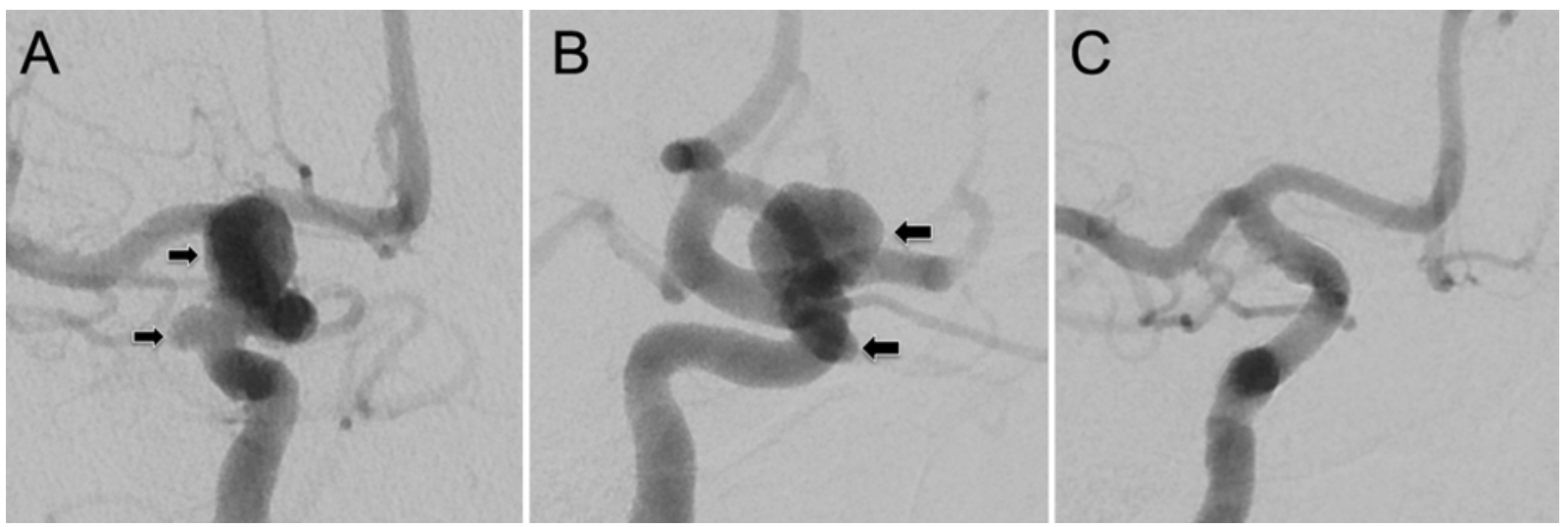

FIG. 1. A: Right ICA angiogram demonstrating a small, laterally directed, 3-mm aneurysm at the anterior genu and a larger, 9-mm ophthalmic artery aneurysm (arrows). B: Same right ICA angiogram in the lateral projection. The anterior genu aneurysm is partially obscured by the course of the ICA (arrows). C: One-year follow-up angiogram demonstrating complete occlusion of both aneurysms.

flow diversion for the treatment of tandem cerebral aneurysms has an acceptable safety profile and can be an effective therapy for a complicated subset of patients. We successfully treated a wide range of tandem aneurysm types including saccular, blister, and pseudoaneurysms in both the anterior and posterior circulation. Further prospective studies must be performed before more definitive conclusions can be made, but our preliminary results indicate the technique can be safe and effective.

\section{References}

1. Chalouhi N, Zanaty M, Whiting A, Tjoumakaris S, Hasan D,
Ajiboye N, et al: Treatment of ruptured intracranial aneurysms with the Pipeline Embolization Device. Neurosurgery 76:165-172, 2015

2. Chalouhi N, Zanaty M, Whiting A, Yang S, Tjoumakaris S, Hasan D, et al: Safety and efficacy of the Pipeline Embolization Device in 100 small intracranial aneurysms. J Neurosurg 122: 1498-1502, 2015

3. Chiu AHY, Cheung AK, Wenderoth JD, De Villiers L, Rice $\mathrm{H}$, Phatouros CC, et al: Long-term follow-up results following elective treatment of unruptured intracranial aneurysms with the Pipeline Embolization Device. AJNR Am J Neuroradiol 36:1728-1734, 2015

4. Dai D, Ding YH, Kadirvel R, Rad AE, Lewis DA, Kallmes DF: Patency of branches after coverage with multiple tele- 
scoping flow-diverter devices: an in vivo study in rabbits. AJNR Am J Neuroradiol 33:171-174, 2012

5. Deutschmann HA, Wehrschuetz M, Augustin M, Niederkorn K, Klein GE: Long-term follow-up after treatment of intracranial aneurysms with the Pipeline Embolization Device: results from a single center. AJNR Am J Neuroradiol 33:481-486, 2012

6. Fang YB, Zhang ZL, Yang PF, Wen WL, Hong B, Xu Y, et al: Stepwise stent deployment technique for tandem intracranial aneurysms: a review of 21 cases. Eur Radiol 26:351358,2016

7. Fiorella D, Hsu D, Woo HH, Tarr RW, Nelson PK: Very late thrombosis of a Pipeline Embolization Device construct: case report. Neurosurgery 67 (3 Suppl Operative):onsE313-onsE314, 2010

8. Fiorella D, Woo HH, Albuquerque FC, Nelson PK: Definitive reconstruction of circumferential, fusiform intracranial aneurysms with the Pipeline Embolization Device. Neurosurgery 62:1115-1121, 2008

9. Gonzalez NR, Dusick JR, Duckwiler G, Tateshima S, Jahan R, Martin NA, et al: Endovascular coiling of intracranial aneurysms in elderly patients: report of 205 treated aneurysms. Neurosurgery 66:714-721, 2010

10. Huang Q, Xu J, Cheng J, Wang S, Wang K, Liu JM: Hemodynamic changes by flow diverters in rabbit aneurysm models: a computational fluid dynamic study based on microcomputed tomography reconstruction. Stroke 44:1936-1941, 2013

11. Levitt MR, Park MS, Albuquerque FC, Moon K, Kalani MYS, McDougall CG: Posterior inferior cerebellar artery patency after flow-diverting stent treatment. AJNR Am J Neuroradiol 37:487-489, 2016

12. Lin N, Brouillard AM, Xiang J, Sonig A, Mokin M, Natarajan SK, et al: Endovascular management of adjacent tandem intracranial aneurysms: utilization of stent-assisted coiling and flow diversion. Acta Neurochir (Wien) 157:379-387, 2015

13. Lylyk P, Miranda C, Ceratto R, Ferrario A, Scrivano E, Luna $\mathrm{HR}$, et al: Curative endovascular reconstruction of cerebral aneurysms with the Pipeline Embolization Device: the Buenos Aires experience. Neurosurgery 64:632-643, N6, 2009

14. Mazur MD, Kilburg C, Wang V, Taussky P: Pipeline Embolization Device for the treatment of vertebral artery aneurysms: the fate of covered branch vessels. J Neurointerv Surg 8:1041-1047, 2016

15. Molyneux AJ, Kerr RSC, Yu LM, Clarke M, Sneade M, Yarnold JA, et al: International subarachnoid aneurysm trial (ISAT) of neurosurgical clipping versus endovascular coiling in 2143 patients with ruptured intracranial aneurysms: a randomised comparison of effects on survival, dependency, seizures, rebleeding, subgroups, and aneurysm occlusion. Lancet 366:809-817, 2005

16. Nelson PK, Lylyk P, Szikora I, Wetzel SG, Wanke I, Fiorella D: The Pipeline Embolization Device for the intracranial treatment of aneurysms trial. AJNR Am J Neuroradiol 32:34-40, 2011

17. Nelson SJ: Multivoxel magnetic resonance spectroscopy of brain tumors. Mol Cancer Ther 2:497-507, 2003

18. Nossek E, Chalif DJ, Chakraborty S, Lombardo K, Black KS, Setton A: Concurrent use of the Pipeline Embolization Device and coils for intracranial aneurysms: technique, safety, and efficacy. J Neurosurg 122:904-911, 2015

19. Park MS, Kilburg C, Taussky P, Albuquerque FC, Kallmes DF, Levy EI, et al: Pipeline Embolization Device with or without adjunctive coil embolization: analysis of complications from the IntrePED registry. AJNR Am J Neuroradiol 37:1127-1131, 2016

20. Park MS, Nanaszko M, Sanborn MR, Moon K, Albuquerque
FC, McDougall CG: Re-treatment rates after treatment with the Pipeline Embolization Device alone versus Pipeline and coil embolization of cerebral aneurysms: a single-center experience. J Neurosurg 125:137-144, 2016

21. Rinne J, Hernesniemi J, Puranen M, Saari T: Multiple intracranial aneurysms in a defined population: prospective angiographic and clinical study. Neurosurgery 35:803-808, 1994

22. Roy D, Milot G, Raymond J: Endovascular treatment of unruptured aneurysms. Stroke 32:1998-2004, 2001

23. Saatci I, Yavuz K, Ozer C, Geyik S, Cekirge HS: Treatment of intracranial aneurysms using the pipeline flow-diverter embolization device: a single-center experience with longterm follow-up results. AJNR Am J Neuroradiol 33:14361446,2012

24. Siddiqui AH, Kan P, Abla AA, Hopkins LN, Levy EI: Complications after treatment with Pipeline embolization for giant distal intracranial aneurysms with or without coil embolization. Neurosurgery 71:E509-E513, 2012

25. Solander S, Ulhoa A, Viñuela F, Duckwiler GR, Gobin YP, Martin NA, et al: Endovascular treatment of multiple intracranial aneurysms by using Guglielmi detachable coils. J Neurosurg 90:857-864, 1999

26. Szikora I, Berentei Z, Kulcsar Z, Marosfoi M, Vajda ZS, Lee $\mathrm{W}$, et al: Treatment of intracranial aneurysms by functional reconstruction of the parent artery: the Budapest experience with the Pipeline Embolization Device. AJNR Am J Neuroradiol 31:1139-1147, 2010

27. van der Schaaf I, Algra A, Wermer M, Molyneux A, Clarke M, van Gijn J, et al: Endovascular coiling versus neurosurgical clipping for patients with aneurysmal subarachnoid haemorrhage. Cochrane Database Syst Rev (4):CD003085, 2005

28. Vlak MH, Algra A, Brandenburg R, Rinkel GJ: Prevalence of unruptured intracranial aneurysms, with emphasis on sex, age, comorbidity, country, and time period: a systematic review and meta-analysis. Lancet Neurol 10:626-636, 2011

29. Xavier AR, Rayes M, Pandey P, Tiwari A, Kansara A, Guthikonda M: The safety and efficacy of coiling multiple aneurysms in the same session. J Neurointerv Surg 4:2730,2012

30. Xiang J, Damiano RJ, Lin N, Snyder KV, Siddiqui AH, Levy EI, et al: High-fidelity virtual stenting: modeling of flow diverter deployment for hemodynamic characterization of complex intracranial aneurysms. J Neurosurg 123:832-840, 2015

\section{Disclosures}

Dr. Taussky is a consultant for Covidien/Medtronic. Dr. McDougall is a consultant for ev3, MicroVention, and Aashish Tech.

\section{Author Contributions}

Conception and design: Park, McDougall, Albuquerque. Acquisition of data: Awad, Moon, Yoon, Mazur. Analysis and interpretation of data: Park, Awad, Moon, Yoon, Mazur. Drafting the article: Park, Awad. Critically revising the article: Park, Awad, Kalani, Taussky, McDougall, Albuquerque. Reviewed submitted version of manuscript: Park, Awad, Taussky, McDougall, Albuquerque. Approved the final version of the manuscript on behalf of all authors: Park.

\section{Correspondence}

Min S. Park, Department of Neurosurgery, Clinical Neurosciences Center, University of Utah, 175 N Medical Dr. East, Salt Lake City, UT 84132. email: neuropub@hsc.utah.edu. 